\title{
Orbital indices in a modern Sinhalese Sri Lankan population
}

\author{
Navneet Lal ${ }^{1}$, Jon Cornwall ${ }^{1,2,3}$, George J. Dias ${ }^{4}$ \\ ${ }^{1}$ Department of Physiology, University of Otago, Dunedin, New Zealand \\ ${ }^{2}$ Graduate School of Nursing, Midwifery and Health, Victoria University of Wellington, Wellington, New Zealand \\ ${ }^{3}$ Institute for Health Sciences, Zurich University of Applied Science, Zurich, Switzerland \\ ${ }^{4}$ Department of Anatomy, University of Otago, Dunedin, New Zealand
}

\begin{abstract}
Objectives: An understanding of orbital morphology is relevant to forensic identification, craniofacial surgery, and anthropological analysis. Orbital index (OI), the relationship between the height and width of the orbit, varies between different populations of humans. This study examines modern Sinhalese Sri Lankan skulls to determine normal values for OI and explore how OI may vary with laterality and sex.

Methods: Measurements of fifty modern Sinhalese Sri Lankan skulls (origin Central Province, Sri Lanka) of known sex (34 male and 16 female) were undertaken for orbital height and width (bilaterally) using a digital caliper. Ol was calculated using a standard formula ([orbital breadth / orbital height] $\times 100$ ). Statistical tests analysing Ol and size for both sex and laterality were performed using unpaired and paired 2-tailed t-tests $(p<0.05)$, respectively.

Results: Overall mean ( \pm standard deviation) Ol was 81.29 \pm 6.14 , with significant differences found between males (79.29 \pm 5.65 ) and females (84.39 \pm 5.59$)$ Ol. Left Ol was significantly greater than right in both males $(80.74 \pm 5.85$ vs. $77.83 \pm 5.11)$ and females $(85.47 \pm 5.70$ vs. $83.31 \pm 5.39)$, indicating Ol asymmetry. Individual heights and breadths of the orbits were symmetrical in both males and females.

Conclusion: Findings indicate Ol asymmetry (left larger than right OI) and sexual dimorphism in this population of modern Sinhalese Sri Lankan skulls. Male orbits were microseme $(\mathrm{Ol}<83)$ and female mesoseme $(\mathrm{Ol} 83-89)$, an unexpected finding as Asian populations supposedly have megaseme (Ol>89) orbits, therefore challenging previous assumptions on ethnic Ol norms.
\end{abstract}

Keywords: measurement; orbit; orbital index; Sinhalese Sri Lankan

Anatomy 2016;10(3):205-210 C2016 Turkish Society of Anatomy and Clinical Anatomy (TSACA)

\section{Introduction}

The orbits are craniofacial structures situated on either side of the sagittal plane within the skull that encroach equally upon the cranial and facial regions. Each orbit is composed of several bones arranged to form quadrilateral pyramids with their bases facing anterolaterally and slightly downward, and their apices projecting posteriomedially. ${ }^{[1-3]}$ The orbits contain and protect the eyes, extra-ocular muscles and several neurovascular structures, and also allow for the accurate positioning of the visual axis, ${ }^{[1,4]}$ which is essential for binocular vision. As landmark features of the skull, morphometric characterisation of the orbits is of value for anthropology, ${ }^{[5]}$ tracing population origins, gaining insight into craniofacial growth due to racial and sexual differences, ${ }^{[6]}$ and quantifying intraspecific variations and forensic osteology. ${ }^{[1,2,4,7]}$ Moreover, comprehensive assessment and preoperative planning in areas of neurosurgery, craniofacial surgery, congenital disfigurement and trauma require specific morphometric data on orbit morphology for the safety and efficacy of clinical treatment..$^{[8-11]}$

While orbit morphology has not changed significantly over recent human history, advances in surgical practice means that we are now able to utilise more detailed and specific information for the treatment of patients. ${ }^{[12]}$ Thus, obtaining data elucidating intraspecific variation, such as left right symmetry (laterality), sex, and racial differences in the morphological parameters of the orbit 
will allow an increased depth, breadth and specificity of knowledge on orbital morphology. One well utilized parameter of orbital morphology is the orbital index (OI) which is defined as a ratio between the orbital height to its width (multiplied by 100). ${ }^{[13]}$ The use of this parameter is favoured for several reasons: 1) the OI is standardized and can be measured in the living and deceased, 2) measurement is rapid and trivial, 3) OI allows for the numerical quantification of descriptive features, and 4) numerous authors have published OI data on several populations, such that the development of a race and sex specific database can possibly be considered. From previous data, three categories of OI have emerged. ${ }^{[14-20]}$ Megaseme describes an OI of $\geq 89$ and is supposedly typically seen in Mongoloid races with the exception of Inuits, while mesoseme describes an OI between 89 to 83 and is typically seen in Caucasians. ${ }^{[1,21]}$ Microseme describes an OI of $\leq 83$ and is typically seen in African races. ${ }^{[1,21]}$

The following study aims to describe normal values and variations of OI found within a contemporary population of Sinhalese Sri Lankans. The study examines and described the relationships between OI, orbital shape, laterality and sex within these skulls with a view to inform and expand current knowledge of OI and orbital morphology.

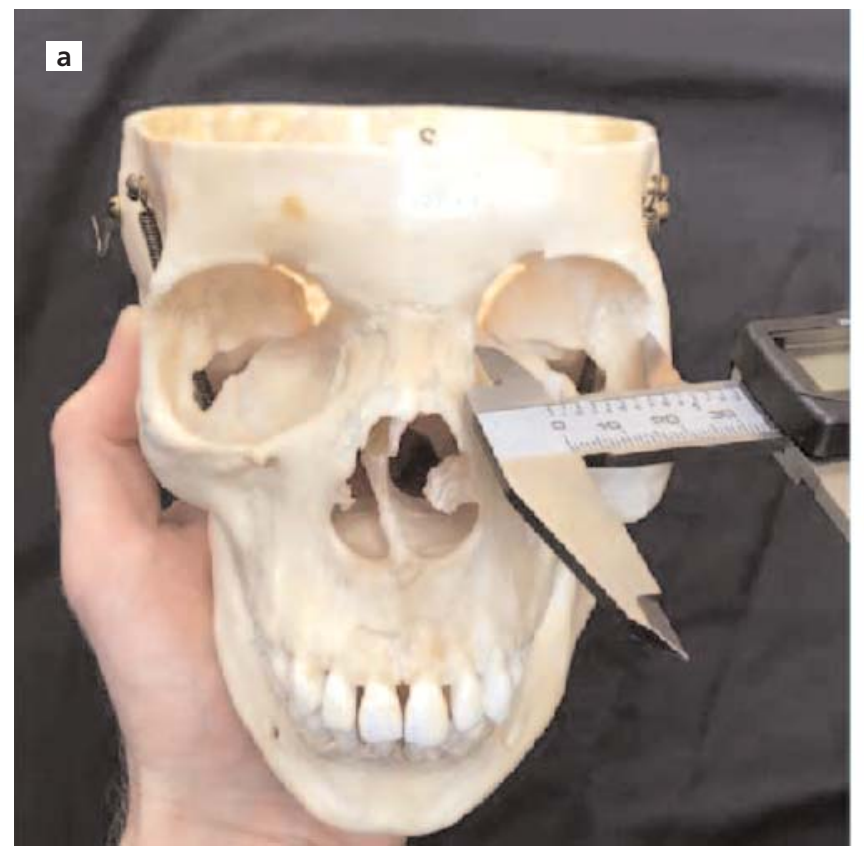

Figure 1. Demonstration of orbital measurements using a digital caliper. Measuring the width (a) and height (b) of the left orbit. [Color figure can be viewed in the online issue, which is available at www.anatomy.org.tr]

\section{Materials and Methods}

Fifty modern Sinhalese Sri Lankan skulls of known sex (34 male and 16 female, from Central Province, Sri Lanka) were measured for orbital height and width using digital calipers (Tresna 0-150 mm digital caliper with $0.03 \mathrm{~mm}$ accuracy; Thermo Fisher, Auckland, New Zealand) (Figure 1) by a single individual with ten years experience in anatomy teaching and research. Skulls with any evidence of trauma or other lesions (e.g. disease) that may affect measurements of the orbit were excluded from the study. Measurement methodology was determined by consensus within the research team in consultation with published methods in the field; the research team included a maxillofacial surgeon with a $\mathrm{PhD}$ in anatomy and twenty years research experience (author GD). OI was calculated using a standard formula - [orbital breadth / orbital height $] \times 100$. Measurements were recorded and analyses performed using Microsoft Excel (Microsoft Corp., Albuquerque, NM, USA). Statistical tests assessing OI and size for both sex and laterality were performed using paired and unpaired 2-tailed homoscedastic t-tests $(\mathrm{p}<0.05)$, respectively. All experimental procedures were undertaken in accordance with the Declaration of Helsinki on medical ethics; experimental protocols met local institutional ethical guidelines as per similar research on human remains held by an academic institution. ${ }^{[2,23]}$

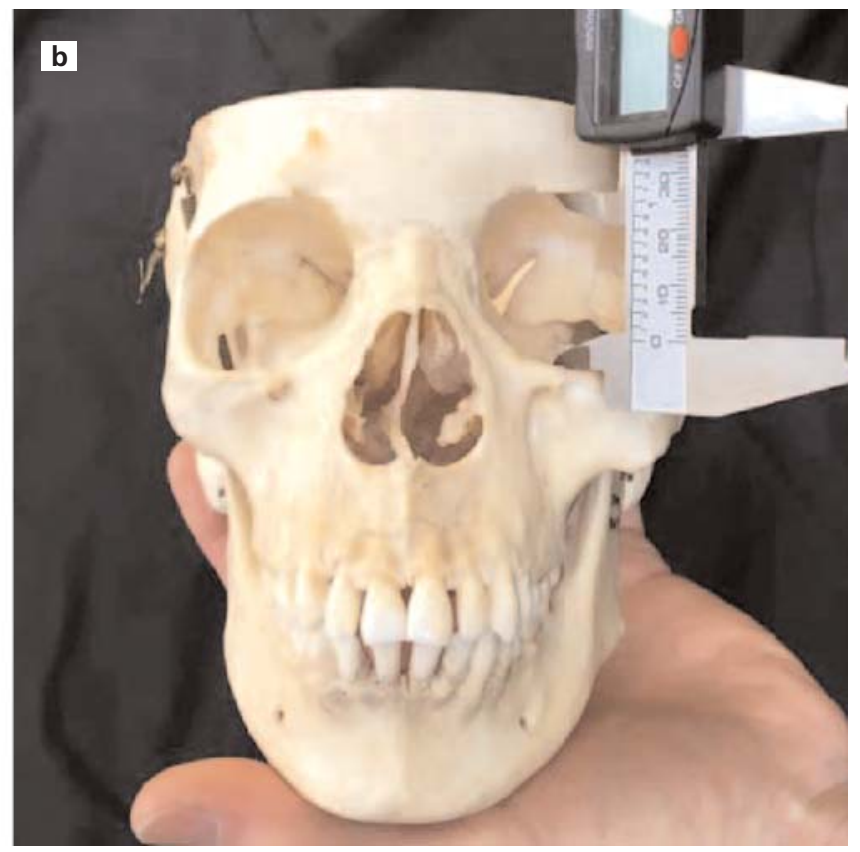




\section{Results}

Bilateral measurements from all 50 skulls were analysed. Overall mean ( \pm standard deviation) OI for this population was $81.29 \pm 6.02$, with mean male OI being significantly smaller than female OI $(79.29 \pm 5.48$ vs. $84.39 \pm 5.55$; $\mathrm{p}<0.001$ ), respectively (Table $\mathbf{1})$. The left OI was significantly greater than right in both males $(80.74 \pm 5.85 \mathrm{vs}$. $77.83 \pm 5.11 ; \mathrm{p}<0.0001)$ and females $(85.47 \pm 5.70 \mathrm{vs}$. $83.31 \pm 5.39 ; \mathrm{p}=0.032$ ), with significant differences also seen between males and females for both the left $(\mathrm{p}=0.0043)$ and right $(\mathrm{p}<0.001)$ sides, respectively, indicating OI asymmetry. The breadths of orbits were significantly different between males and females, with orbital breadth larger in males than in females for both left $(p<0.001)$ and right $(p<0.001)$ orbits (Table 1). The measurements for heights of orbits showed no significant difference for laterality or sex.

\section{Discussion}

In this population of contemporary Sinhalese Sri Lankan skulls, the mean OI was $81.29 \pm 6.02$ which places them in the microseme category. However, there were significant differences between males $(79.29 \pm 5.48)$ and females $(84.39 \pm 5.55)$ such that males were classified as microseme, while females as mesoseme. These differences appear to be the result of differences found in the breadths of the orbits, with male orbits being significantly wider than female orbits. Moreover, while individual orbital parameters such as height and breadth were symmetrical, orbital indices displayed left-right asymmetry. The left OI tended to be slightly smaller than the right $\mathrm{OI}$ in both males and females.

\section{Orbital index}

Previous studies describing OI in Asian populations found these populations typically characterized as megaseme (Table 2). ${ }^{[2,25]}$ However, our data shows that contemporary Sinhalese Sri Lankan males are microseme whilst females fit the mesoseme category. This is discrepant in two ways. First, microseme categorisation of our skulls appears to suggest that the orbits have a more rounded morphology than other Asian populations. ${ }^{[1]}$ When this is analyzed against other data from Asian population, it appears that this discrepancy is evident with most of the data available on Egyptian $^{[2]}$ and Indian subpopulations. ${ }^{[12,14,1,1,18,19,21,26,27]}$ Second, Asian populations seldom display OI sexual dimorphism (Table 2). However, this was clearly evident within the Sinhalese population, and may reflect the selection pressures placed on the sexes within the population.

Orbital heights were consistent between males and females, and displayed left-right symmetry. The left $(32.74 \pm 1.96 \mathrm{~mm}$ vs. $32.65 \pm 1.94 \mathrm{~mm})$ and right $(32.24 \pm 2.19$ $\mathrm{mm} v s .32 .35 \pm 1.93 \mathrm{~mm}$ ) orbital heights of both males and females respectively were within the range of with other neighbouring populations in India ${ }^{[12,14,15,18,19,21,26,27]}$ but smaller than Egyptian, ${ }^{[2]}$ Korean, ${ }^{[24]}$ andmost African populations (Table 2). ${ }^{[9,13,17,28,29]}$ Orbital breadth was larger in males $(40.63 \pm 1.92 \mathrm{~mm}, 41.47 \pm 1.94 \mathrm{~mm}$; left and right sides, respectively) than females $(38.27 \pm 2.1 \mathrm{~mm}, 38.91 \pm 2.39$ $\mathrm{mm}$; left and right sides, respectively). These values were larger than those seen in Korean populations, ${ }^{[24]}$ smaller than Egyptian ${ }^{[2]}$ and most African populations, but within the range of most Indian populations (Table 2). ${ }^{[12,14,15,18,1,2,21,26,27]}$

\section{Laterality}

Individually, the left and right orbital heights and breadths in males and females were not significantly different, suggesting left and right symmetry. However, when these parameters were used to derive OI, differences between the left and right sides in males and females became apparent. This indicates that individually, the differences found between the left and right side orbital height and width were not large enough to be detected by our statistical tests. Left-right asymmetry in orbital height or breadth was previously reported in Egyptian ${ }^{[2]}$ and Nigerian ${ }^{[2]}$ populations; morphological asymmetry is not unique to this region and was identified in other morpho-

Table 1

Data and analyses of orbital size and indices of modern Sinhalesle Sri Lankan skulls from Central Province.

\begin{tabular}{|c|c|c|c|c|c|c|c|}
\hline & $\mathrm{n}$ & $\begin{array}{c}\text { Left orbital } \\
\text { height }\end{array}$ & $\begin{array}{l}\text { Right orbital } \\
\text { height }\end{array}$ & $\begin{array}{l}\text { Left orbital } \\
\text { breadth }\end{array}$ & $\begin{array}{l}\text { Right orbital } \\
\text { breadth }\end{array}$ & $\begin{array}{l}\text { Left orbital } \\
\text { index }\end{array}$ & $\begin{array}{l}\text { Right orbital } \\
\text { index }\end{array}$ \\
\hline All & 50 & $32.71 \pm 1.94$ & $32.28 \pm 2.07$ & $39.7 \pm 2.29$ & $40.46 \pm 2.46$ & $82.6 \pm 6.2$ & $79.98 \pm 5.84$ \\
\hline Males & 34 & $32.74 \pm 1.96$ & $32.24 \pm 2.19$ & $40.63 \pm 1.9 *$ & $41.47 \pm 1.94^{*}$ & $80.74 \pm 5.85^{\dagger}$ & $77.83 \pm 5.11$ * \\
\hline Females & 16 & $32.65 \pm 1.94$ & $32.35 \pm 1.93$ & $38.27 \pm 2.1$ & $38.91 \pm 2.39$ & $85.47 \pm 5.7^{\dagger}$ & $83.31 \pm 5.39$ \\
\hline
\end{tabular}

${ }^{*} \mathrm{p}<0.05$ females vs males (unpaired 2-tailed homoscedastic $\mathrm{t}$-test); $\mathrm{t} p<0.05$ left vs right (paired 2-tailed homoscedastic $\mathrm{t}$-test) 
Table 2

Orbital indices data from this study and previously published work. Data from this study on the orbital indices of Sinhalese Sri Lankan skulls is presented for comparison with those from other ethnicities by sex and by classification.

\begin{tabular}{|c|c|c|c|c|c|c|c|}
\hline Region & Population & Sex & Number & $\begin{array}{l}\text { Orbital } \\
\text { Index }\end{array}$ & Category & Author & $\begin{array}{l}\text { Method, } \\
\text { Source }\end{array}$ \\
\hline \multirow[t]{16}{*}{ Africa } & Black Kenyan & Male & 80 & 82.57 & Microseme & Munguti et al. ${ }^{[30]} 2013$ & Vernier caliper, dry skulls \\
\hline & & Female & 70 & 83.48 & Mesoseme & & \\
\hline & & Mean & & 83.03 & Mesoseme & & \\
\hline & Malawians & Male & 70 & 94.35 & Megaseme & Igbigbi and Ebite ${ }^{[13]} 2010$ & Ruler, frontal X-ray \\
\hline & & Female & 66 & 96.03 & Megaseme & & \\
\hline & & Mean & & 95.2 & Megaseme & & \\
\hline & Nigerian & Male & 78 & 89.59 & Mesoseme & Orish and Ibeachu ${ }^{[20]} 2016$ & Digital Vernier calipers, dry skulls \\
\hline & & Female & 22 & 87.04 & Mesoseme & & \\
\hline & & Mean & & 88.32 & Mesoseme & & \\
\hline & Nigerian & Male & Unknown & 89.21 & Megaseme & Ukoha et al. ${ }^{[28]} 2011$ & Unknown \\
\hline & Nigerian Binis & Male & 63 & 78.21 & Microseme & Anibor and Ighodae ${ }^{[17]} 2013$ & Vernier caliper, frontal X-ray \\
\hline & & Female & 37 & 75.82 & Microseme & & \\
\hline & & Mean & & 77 & Microseme & & \\
\hline & Nigerian Urhobos & Male & 236 & 78.15 & Microseme & Ebeye and Otkipo ${ }^{[29]} 2013$ & Not stated, living subjects \\
\hline & & Female & 152 & 78.57 & Microseme & & \\
\hline & & Mean & & 78.36 & Microseme & & \\
\hline \multirow[t]{26}{*}{ Asia } & Egyptian & Male & 30 & 82.27 & Microseme & Fetouh and Mandour 2014 & Divider and ruler, dry skulls \\
\hline & & Female & 22 & 83.5 & Mesoseme & & \\
\hline & & Mean & & 82.89 & Microseme & & \\
\hline & Indian & Mean & 68 & 80.07 & Microseme & Kumar and Nagar ${ }^{[12]} 2014$ & Vernier calipers, dry skulls \\
\hline & Indian (North) & Mean & 50 & 82.68 & Microseme & Alam et al. ${ }^{[18]} 2016$ & Vernier calipers, dry skulls \\
\hline & Indian (North) & Male & 60 & 81.15 & Microseme & Maharana and Agarwal[19] 2015 & Manual calipers, dry skulls \\
\hline & & Female & 40 & 82.16 & Microseme & & \\
\hline & & Mean & & 81.66 & Microseme & & \\
\hline & Indian (North) & Mean & 30 & 81.65 & Microseme & Kaur et al..$^{[14]} 2012$ & Vernier calipers, dry skulls \\
\hline & Indian (Central) & Mean & 64 & 81.88 & Microseme & Gosavi et al. ${ }^{[15]} 2014$ & Digital Vernier calipers, dry skulls \\
\hline & Indian (South) & Male & 105 & 84.62 & Mesoseme & Mekala et al. ${ }^{[21]} 2015$ & Manual calipers, dry skulls \\
\hline & & Female & 95 & 85.46 & Mesoseme & & \\
\hline & & Mean & & 85.04 & Mesoseme & & \\
\hline & Indian (South) & Mean & 50 & 88.41 & Mesoseme & Narasinga and Pramila ${ }^{[27]} 2015$ & Vernier calipers, dry skulls \\
\hline & Indian (South) & Male & 130 & 81.13 & Microseme & Patil et al. ${ }^{[26]} 2014$ & Vernier calipers, dry skulls \\
\hline & & Female & 70 & 81.32 & Microseme & & \\
\hline & & Mean & & 81.23 & Microseme & & \\
\hline & Indonesian (Batak) & Unknown & 11 & 99.26 & Megaseme & Novita $^{[25]} 2006$ & Not stated, frontal X-ray \\
\hline & Indonesian (Flores) & Unknown & 10 & 106.63 & Megaseme & Novita $^{[25]} 2006$ & Not stated, frontal X-ray \\
\hline & Indonesian (Klaten) & Unknown & 10 & 102.73 & Megaseme & Novita $^{[25]} 2006$ & Not stated, frontal X-ray \\
\hline & Korean & Male & 41 & 100 & Megaseme & Hwang and Baik' 1999 & Vernier / Marshac calipers, dry skulls \\
\hline & & Female & & 98.55 & Megaseme & & \\
\hline & & Mean & & 99.28 & Megaseme & & \\
\hline & Sinhalese Sri Lankan & Male & 34 & 79.29 & Microseme & Current study & Digital Vernier calipers, dry skulls \\
\hline & & Female & 16 & 84.39 & Mesoseme & & \\
\hline & & Mean & & 81.29 & Microseme & & \\
\hline
\end{tabular}

Orbital indices $(\mathrm{OI})$ are classified in the following manner: Microseme=Ol<83; Mesoseme=OI 83-89; Megaseme=Ol $>89$.

logical features such as the jugular foramen and the superior sagittal sinus. ${ }^{[1]]}$ However, the majority of studies published on OI indicate left-right symmetry, though some of these observed differences were not statistically significant. Left-right orbital index asymmetry is poten- tially a novel finding and may be a characteristic unique to our population of skulls. Previous OI studies seldom included left-right measurements and thereby data on laterality is lacking for many other populations where OI has been studied. 


\section{Sexual dimorphism}

Sexual dimorphism was evident in the orbital breadth and OI, with male skulls exhibiting a larger breadth $(40.63 \pm 1.92 \mathrm{~mm}, 41.47 \pm 1.94 \mathrm{~mm}$; left and right sides, respectively) and smaller OI (79.29) than female skulls $(38.27 \pm 2.1 \mathrm{~mm}, 38.91 \pm 2.39 \mathrm{~mm}$; left and right breadths respectively; $\mathrm{OI}=84.39 \pm 5.55$ ). These data suggest that the females in our population of Sinhalese Sri Lankans had more rounded orbits than the males, whilst male orbits tended to be broader and more rectangular. In previous studies, OI sexual dimorphism was a feature most frequently seen in African ${ }^{[9,13,17,20,24]}$ and Egyptian ${ }^{[2]}$ populations, whereas sexual dimorphism in Indian and other Asian populations $s^{[1,11,15,18,1,2,2,24-27]}$ were not statistically significant. The existence and extent of OI sexual dimorphism might indicate a history of significant selection pressure that was specific to our population of Sinhalese Sri Lankans.

\section{Comparison of methods between studies}

The comparison of data generated in previous studies on OI is difficult due to the diverse nature of the methodologies employed by the various authors. Methods for the studies presented in Table 2 vary between the use of calipers (digital or manual), ${ }^{[12,21]}$ measurement from $\mathrm{X}$ ray ${ }^{[13,25]}$ calculations from living individuals, ${ }^{[29]}$ transfer of measurementsfrom a divider to a ruler, ${ }^{[2]}$ or methods not being clearly enough stated to allow reproduction of the study. ${ }^{[28]}$ Reliable measurements of orbital dimensions from an X-ray is particularly problematic given the potential for error in generating a measurement of an image $(X-$ ray) that displays a two-dimension representation of a structure that has a three-dimensional morphology (heigh, width and depth). It is also not clear whether measurements from X-rays were normalized by calibration to account for any possible image distortion. Measurements from living individuals also create difficulty for investigators looking to reliably identify orbital margins and accurately determine maximum breadth and height in each case. In addition, some sample sizes in other studies are very small and may not be representative of the populations studied. ${ }^{[2]}$ Further, there are no consistently applied guidelines or criteria that studies follow which would allow confidence in the reliability of the measurement of the orbit and subsequent calculation of OI. Although the orbital measurements are recorded by taking the maximum orbital height and breadth, a standardized set of guidelines should be developed and utilized for this purpose to generate consistency of reporting and allow accurate comparison of future data. It is therefore suggested that any comparison between OI data in the presented studies (Table 2) be undertaken with caution given the variation in utilised methodologies.

\section{Limitations}

There is the potential for older, damaged, or well-handled skulls to be difficult to examine, especially if there is any damage around the orbital margins. None of the skulls used in this study had damage to the orbit that affected the measurement or recording. The sample size was small, in particular for the female skulls; despite this, the data do provide useful information from which to undertake a study with a larger sample size given the confirmation of variation in orbital morphology both between and within sexes. There was the potential for intra-observer variation of the recorded measurements; however, members of the research team oversaw practice of the technique to ensure consistency and repeatability, and the recorder was an anatomist who was experienced insuch measurements (e.g. bony measurement using digital calipers), thereby minimising the potential for overt measurement errors.

\section{Conclusion}

Modern Sinhalese Sri Lankan male orbits can be classified as microseme $(\mathrm{OI}<83)$ and female as mesoseme $(\mathrm{OI}=83$ 89), which is an unusual finding given many Asian populations are said to have megaseme (OI>89) orbits. This challenges previous suggestions regarding ethnic categorization and possible lack of ethnic variation for this morphological measure. Our findings identified the presence of left-right OI asymmetry (left larger than right OI) and sexual dimorphism in this population. This is a feature which has not been identified in neighbouring Indian populations and may be a characteristic unique to contemporary Sinhalese Sri Lankans.

\section{References}

1. Xing S, Gibbon V, Clarke R, Liu W. Geometric morphometric analyses of orbit shape in Asian, African, and European human populations. Anthropological Science 2013;121:1-11.

2. Fetouh FA, Mandour D. Morphometric analysis of the orbit in adult Egyptian skulls and its surgical relevance. Eur J Anat 2014;18:30315.

3. Kumar SS, Gnanagurudasan E. Morphometry of bony orbit related to gender in dry adult skulls of South Indian population. International Journal of Health Sciences and Research 2015;5:20714.

4. Pires LAS, Teixeira AR, Leite TFO, Babinski MA, Chagas CAA. Morphometric aspects of the foramen magnum and the orbit in Brazilian dry skulls. International Journal of Medical Research and Health Sciences 2016;5:34-42.

5. Oladipo GS, Olotu JE, Suleiman Y. Anthropometric studies of cephalic indices of the Ogonis in Nigeria. Asian J Med Sci 2009;1: $15-17$.

6. Evereklioglu C, Doganay S, Er H, Gunduz A, Tercan M, Balat A, Cumurcu T. Craniofacial anthropometry in a Turkish population. Cleft Palate Craniofac J 2002;39:208-18. 
7. Giles E, Elliot O. Race identification from cranial measurements. J Forensic Sci 1962;7:147-57.

8. Lo LJ, Marsh JL, Kane AA, Vannier MW. Orbital dysmorphology in unilateral coronal synostosis. Cleft Palate Craniofac J 1996;33: 190-7.

9. Munguti J, Mandela P, Butt F. Referencing orbital measures for surgical and cosmetic procedures. Anatomy Journal of Africa 2012;1:405 .

10. ChengAC, Lucas PW, Yuen HK, Lam DS, So KF. Surgical anatomy of the Chinese orbit. Ophthal Plast Reconstr Surg 2008;24:13641.

11. Rehman KU, Shetty S, Williams R. An orbital depth guide for the repair of the orbital floor. Br J Oral Maxillofac Surg 2008;46:338.

12. Kumar A, Nagar M. Morphometry of the orbital region: "Beauty is bought by judgment of the eyes." International Journal of Anatomy and Research 2014;2:566-70.

13. Igbigbi PS, Ebite LE. Orbital index of adult Malawians. Anil Aggrawal's Internet Journal of Forensic Medicine and Toxicology 2010;11:1

14. Kaur J, Ydav S, Singh Z. Orbital dimensions - A direct measurement study using dry skulls. Journal of Academia and Industrial Research 2012;1:293-5.

15. Gosavi SN, Jadhav SD, Zambre BR. A study of orbital morphometry in Indian dry skulls. Asian Journal of Biomedical and Pharmaceutical Sciences 2014a;4:23-5.

16. Gosavi SN, Jadhav SD, Zambre BR. Orbital morphology with reference to bony landmarks. Revista Argentina de Anatomia Clinica 2014b;6:20-5.

17. Anibor E, Ihodae W. Orbital index of adult Binis in Edo State, Nigeria. International Journal of Forensic Medical Investigation 2015;2:17-9.

18. Alam MT, Rai R, Singh MK. Orbital dimensions and orbital index of adult human dry skulls: a direct measurement study. International Journal of Science and Research 2016;5:523-4.

19. Maharana SS, Agarwal RK. Variations in the dimensions of the orbit in the adult human skull (a dry bone study). International Journal of Recent Biotechnology 2015;3:20-2.

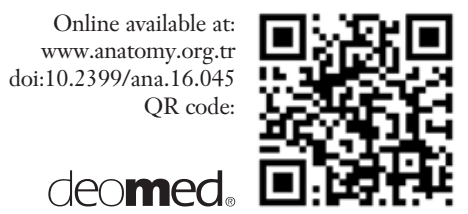

20. Orish CN, Ibeachu PC. Craniometric indices of Nigeria skulls. International Journal of Anatomy and Applied Physiology 2016;2:613.

21. Mekala D, Shubha R, Rohini Devi M. Orbital dimensions and orbital index: A measurement study on South Indian dry skulls. International Journal of Anatomy and Research 2015;3:1387-91.

22. Cornwall J, Stringer MD, Duxson M. The functional morphology of the thoracolumbar transversospinal muscles. Spine (Phila Pa 1976) 2011;36:E1053-61.

23. Cornwall J, Samarakoon L, Antony DJ, Dias GJ. Morphological and degenerative changes in a post-traumatic bifid mandibular condyle. Anatomy 2014:8:27-31.

24. Hwang K, Baik SH. Surgical anatomy of the orbit of Korean adults. J Craniofac Surg 1999;10:129-34.

25. Novita M. Facial, upper facial, and orbital index in Batak, Klaten, and Flores students of Jember University. Dental Journal (Majalah Kedokteran Gigi) 2006;39:116-9.

26. Patil GV, T Shishirkumar, D Apoorva, Sharif J, Sheshgiri C, Sushanth NK. Study of orbital index in human dry skulls of South Indian origin. Int J Health Sci Res 2014;4:125-8.

27. Narasinga RB, Pramila PM. A study of orbital index in dry skulls of North Coastal Andhra Pradesh. International Journal of Basic Applied Medical Sciences 2015;5:1-3.

28. Ukoha U, Egwu OA, Okafor IJ, Oguagu PC, Onwudingo O, Udemezue OO. Orbital dimensions of adult male Nigerians: a direct measurement study using dry skulls. Int J Biol Med Res 2011;2:68890.

29. Ebeye OA, Otikpo O. Orbital index in Urhobos of Nigeria. IOSR Journal of Dental and MedicalSciences 2013;8:51-3.

30. Munguti J, Mandela P, Butt F. Sex differences in the cranial and orbital indices for a black Kenyan population. International Journal of Medical Sciences 2013;5:81-4.

31. Dias GJ, Perumal V, Smith C, Cornwall J. The relationship between jugular foramen asymmetry and superior sagittal sinus laterality. Anthropological Science 2014;122:115-20.

Correspondence to: George Dias, PhD

Department of Anatomy, University of Otago,

PO Box 56, Dunedin, New Zealand

Phone: +6434797092

e-mail: george.dias@anatomy.otago.ac.nz

Conflict of interest statement: No conflicts declared.

This is an open access article distributed under the terms of the Creative Commons Attribution-NonCommercial-NoDerivs 3.0 Unported (CC BY-NCND3.0) Licence (http://creativecommons.org/licenses/by-nc-nd/3.0/) which permits unrestricted noncommercial use, distribution, and reproduction in any medium, provided the original work is properly cited. Please cite this article as: Lal N, Cornwall J, Dias GJ. Orbital indices in a modern Sinhalese Sri Lankan population. Anatomy 2016;10(3):205-210. 